\title{
Da transformação de conflitos à paz híbrida: uma análise das ideias de John Paul Lederach e Roger Mac Ginty ${ }^{1}$
}

\section{From Conflict Transformation to Hybrid Peace: an analysis of John Paul Lederach and Roger Mac Ginty's ideas}

\section{AUREO TOLEDO JULIA FACCHINI}

\section{INTRODUÇÃO}

A construção da paz consiste em processos contínuos e a longo prazo que buscam reconstituir sociedades saídas de conflitos não apenas a nível estatal, mas também em termos de sociabilidade, a fim de que a população local possa conviver, ao menos idealmente, de forma harmônica. Essas ações, largamente conhecidas como processos de peacebuilding, podem ser entendidas sob diversas vertentes. Usualmente as Nações Unidas as definem como ações destinadas à contenção do conflito mediante o fortalecimento das capacidades nacionais, buscando desenvolver bases para a paz e desenvolvimento sustentáveis. É um projeto de alta complexidade, especialmente porque o foco das atividades é reduzir ou extinguir problemas estruturais que desencadearam o conflito. O conceito é amplamente investigado nos estudos para a paz e é ressignificado de acordo com o que as diferentes abordagens propõem. Nesse sentido, a virada local, movimento composto por autoras e autores distintos que consideram a dinâmica local como fundamental para a reconstrução da sociedade pós-conflito, compreende o peacebuilding como um processo que engloba a população nos esforços de pacificação e reestruturação da sociedade, considerando-a como agente para uma paz emancipatória (Schierenbeck 2015).

Aureo Toledo - Universidade Federal de Uberlândia.

Julia Facchini - Universidade Federal de Uberlândia. 
O modelo da paz liberal, entendido como um sistema de intervenções formais de promoção da paz em sociedades permeadas por conflitos, se tornou mais proeminente após o final da Guerra Fria, em um cenário dominado pela primazia dos valores ocidentais e pelo aumento significativo de conflitos civis que geraram, como consequência, um aumento na quantidade de operações de peacekeeping ${ }^{2}$. A paz liberal está, então, interessada na expansão das liberdades individuais, na racionalidade dos indivíduos e coletividades e na defesa das leis, da propriedade, do livre mercado e da organização societária baseada no Estado (Mac Ginty 2011).

De acordo com Mac Ginty e Richmond (2013), os estudos para a paz são, por natureza, críticos: ao tomarem a paz como objeto de estudo ao invés da guerra, distanciam-se das abordagens ortodoxas das Relações Internacionais e da Ciência Política. Esses estudos buscam, portanto, questionar a atuação internacional na resolução de conflitos e na construção da paz, visto que esta, via de regra, culmina na implementação de modelos políticos e econômicos que não são pertinentes à realidade local. Em termos de produção crítica, é possível dividi-las em três grupos.

As críticas reformistas não questionam as propostas de liberalização econômica e de democratização política, mas sim o modo como são implementadas, levando em conta o grau de institucionalização e as condições locais para que a população leve a cabo o novo arcabouço trazido pelas operações de paz. As críticas estruturais, por outro lado, são pautadas por ideias neogramscianas e pós-estruturalistas e compreendem os conflitos enquanto resultados da ordem capitalista mundial e as operações de peacebuilding como mecanismos biopolíticos de manutenção dessas estruturas capitalistas. Por sua vez, a virada local surge enquanto abordagem que busca rever a paz liberal e suas práticas a partir da inserção do local enquanto componente central das análises sobre processos de construção da paz. Apesar das diversas vertentes analíticas utilizadas pelos autores desse movimento, considera-se, de modo geral, que a agência local nos processos de peacebuilding tem potencial para promover a paz, visto que as demandas dessa população seriam, em tese, consideradas (Gomes 2013).

Dentro desse grande universo, dois autores têm espaço privilegiado. John Paul Lederach, pesquisador estadunidense, é o principal nome do que se chama de primeira virada local e visa, em suas obras, tratar da paz enquanto um processo que abarca uma série de fatores antes não considerados, especialmente aqueles fatores específicos de cada comunidade. Dessa forma, não existem padrões preestabelecidos para tal processo, visto que cada ambiente possui suas características próprias que respondem a ações diferentes. Roger Mac Ginty, pesquisador da Universidade de Manchester, compõe o que se convencionou chamar segunda virada local e parte do 
hibridismo entre o local e o internacional para propor alternativas ao estabelecimento da paz. Sendo assim, mediante uma revisão bibliográfica de obras selecionadas de Lederach e Mac Ginty, o objetivo desse artigo consiste em compreender as diferenças e semelhanças entre as propostas dos autores, partindo da concepção do que é o "local" para ambos. Ainda que modesto, a proposta do artigo se justifica, na medida em que, salvo melhor juízo, contribuímos para a introdução na academia brasileira das ideias de duas referências no debate, assim como sistematizamos seus principais argumentos.

O artigo está dividido em quatro seções, excetuando-se essa introdução. Inicialmente, apresentamos a virada local enquanto corrente analítica em que os autores se localizam. Em seguida, discutimos as ideias de Lederach, seguidas pelas de Mac Ginty. Finalmente, tecemos nossas considerações finais.

\section{A VIRADA LOCAL}

A construção da paz em sociedades pós-conflito é guiada, atualmente, pela chamada paz liberal. Esse modelo tem por objetivo propor ações cujos objetivos principais são democratização, estabelecimento do Estado de Direito, proteção dos direitos humanos e promoção de uma economia orientada ao mercado. Ademais, como aponta Mac Ginty (2011), a paz liberal formata as operações de paz, mas deve-se ter em mente que os processos liberais de peacebuilding são distintos entre si por diversos fatores, como a abrangência do conflito e a resposta por parte da população local.

Nos últimos anos, nota-se uma tendência na expansão dos estudos internacionais que consideram dinâmicas subnacionais em suas análises. Isso se deve à necessidade de aprofundar conhecimentos acerca do impacto que os interesses e atividades locais exercem sobre as esferas nacionais. Essa tendência se refletiu nos estudos para a paz, especialmente ao se considerar que as raízes dos conflitos, geralmente, estão vinculadas a uma localidade específica. Assim, agendas locais podem ser fontes de conflitos violentos que repercutem em todo o país, ainda que essas agendas sejam geograficamente restritas. A partir desse entendimento, pode-se concluir que as vertentes estritamente focadas na ação estatal não são capazes de estabelecer mecanismos sustentáveis para a solução do conflito, visto que causas importantes não são consideradas (Leonardsson; Rudd 2015).

De maneira ampla, o local é compreendido como o espaço no qual a paz é desenvolvida a partir dos movimentos de base da sociedade, em contraste com a paz liberal proposta por agentes internacionais. Os estudos centrados nessa dinâmica de construção da paz afirmam que o entendimento local tem, em tese, potencial emancipatório, pois seria baseado na convi- 
vência diária (Richmond 2009). Esses elementos citados devem ser considerados para que construção da paz seja, de fato, sustentável. Entretanto, como salienta parte da literatura crítica sobre o tema, deve-se atentar para que o local não seja romantizado. A romantização reforça estereótipos em relação à população local, como a retomada da concepção do indivíduo enquanto "bom selvagem" pacífico ou a reiteração da posição inferiorizada e subordinada da coletividade.

A virada local, então, pode ser caracterizada como um grupo heterogêneo de pesquisadores que partem da assimilação dos pressupostos supracitados para a composição de análises teóricas e empíricas que levam em conta as dinâmicas locais no processo de construção da paz. Öjendal e Ou (2015) ressaltam que a virada local parte das lacunas anteriores, atribuídas à paz liberal, e faz com que a comunidade internacional exerça um papel muito mais reflexivo diante da gama de atores e suas respectivas agências:

A virada local é como uma terra nullius para a epistemologia da paz liberal, e representa um lugar perigoso e selvagem onde a racionalidade ocidental, com seus discursos de universalidade e modernização, é desafiada de maneiras diferentes. A virada local - que desestabiliza o monopólio das elites nacionais e dos intervenientes para definir questões e soluções - responde, ou até se sobrepõe, a ausência comum de "paz cotidiana" na paz liberal. Esta abordagem exige um papel internacional muito mais reflexivo na construção da paz e, em particular, um relacionamento mais reflexivo com toda a gama de atores da construção da paz, incluindo atores locais, e sua agência, direitos e prioridades (Öjendal; Ou 2015, 933, tradução nossa).

Os estudos associados à virada local iniciaram-se a partir da década de 1990 e podem ser divididos em duas grandes fases. De acordo com Paffenholz (2015), a primeira virada local é baseada nas teorias de resolução de conflitos associadas a estudiosos como Adam Curle e Johan Galtung e tem como propósito interpretar e promover a reconciliação sustentável entre os grupos pertencentes a determinada sociedade conflituosa. O principal autor associado a essa vertente é John Paul Lederach, cuja obra é objeto de estudo do presente trabalho e será apresentada posteriormente. A segunda virada local, por outro lado, inicia-se por volta dos anos 2000 como crítica às operações de reconstruções de Estado ensejadas após os ataques terroristas de 11 de setembro de 2001, cujos principais exemplos são as intervenções no Afeganistão (2001) e Iraque (2003). Os referenciais teóricos aqui mobilizados são autores pós-estruturalistas e pós-coloniais como Michel Foucault e Homi Bhabha e, dentre os principais nomes a serem mencionados, temos Oliver Richmond e Roger Mac Ginty. 
Silva (2012) pontua as principais críticas e lacunas relacionadas à virada local. A primeira delas consiste na dificuldade em se definir o que é o "local”, especialmente em sociedades profundamente divididas. Nessa situação, a complexidade em se definir qual grupo será responsabilizado pela condução das medidas para a construção da paz é somada à dificuldade em definir os limites do local a fim de garantir a autonomia nas decisões. Outra crítica volta-se às limitações do local em termos materiais, visto que as instituições internacionais que provêm recursos para assistência o fazem a partir da demonstração de um plano de ação que se mostre viável. Assim, a própria ação local é dependente do reconhecimento internacional.

Diante do exposto, e partindo da contribuição da virada local nos estudos críticos para a paz, cabe desenvolver a revisão bibliográfica de parte das obras de John Paul Lederach e Roger Mac Ginty proposta pelo artigo. A partir da sistematização de suas principais ideias é, então, possível traçar as semelhanças e diferenças entre a abordagem de ambos.

\section{JOHN PAUL LEDERACH E A TRANSFORMAÇÃO DE CONFLITOS}

John Paul Lederach iniciou sua carreira em instituições de mediação de conflito ligadas a associações religiosas das quais pertencia. A partir dos anos 1990, passou a se dedicar à carreira acadêmica, mas seu trabalho prático exercido previamente atribuiu características peculiares à sua obra. $\mathrm{O}$ autor, de modo geral, estabelece padrões para que os peacebuilders sejam capazes de assimilar a realidade local que comporta e, muitas vezes, sustenta o conflito e propor mecanismos específicos que sejam capazes de transformar tal situação. É importante salientar que Lederach, ao invés de tratar da resolução do conflito, propõe uma transformação deste, que consiste em enxergar os fluxos de conflitos sociais como oportunidades a longo prazo para criar processos de mudanças construtivos que reduzam a violência, aumentem a justiça nas interações e na estrutura social como um todo e que respondam aos problemas cotidianos dos relacionamentos humanos. Assim, a transformação do conflito envolve, além de conter os episódios de violência, promover mudanças individuais, relacionais, estruturais e culturais no epicentro do conflito (Wright 2004).

Lederach dialoga com teorias de negociações internacionais destinadas à resolução de conflitos para elaborar sua abordagem. O estudo dessa categoria de negociações internacionais busca abordar conceitos e habilidades de negociação diplomática e mediação com o objetivo de conter eventos que permeiem a violência, sejam conflitos civis ou não. Dessa forma, atribui-se ao negociador um caráter tecnicista, que leva em conta sua capacidade em conciliar partes em conflito a partir de conhecimentos adquiridos 
em termos de comunicação, oratória e persuasão. $\mathrm{O}$ autor propõe ir além dos processos práticos de resolução de conflitos e amplia a profundidade e a duração dos instrumentos para a construção da paz. Dessa forma, não se rejeita os mecanismos trazidos pelas teorias tradicionais nessa área, mas aponta que a resolução de conflitos não consegue levantar questões essenciais para atingir as principais causas do conflito e, consequentemente, solucioná-los (Lederach 2003).

Com o intuito de melhor discutir suas ideias, convém comparar sua abordagem com a proposta trazida por I. William Zartman. ${ }^{3}$ Zartman afirma que as negociações de paz passam a ser viáveis sobretudo quando as partes se encontram em mútuos e danosos impasses (mutual hurting stalemates), sem perspectivas de solução do conflito. Assim, a necessidade de se alcançar a conciliação é indicada pelo cenário catastrófico, que demonstra que os danos serão muito maiores se nada for feito imediatamente. Logo, para Zartman existe um momento crucial para que a negociação seja efetivada, o qual é denominado ripe moment, no qual as partes não têm outra alternativa a não ser cooperar para a paz (Zartman 2003). Em contraposição, Lederach argumenta que a paz pode ser cultivada e fomentada até mesmo antes e durante o conflito direto e não ser perseguida apenas em um momento específico (Lederach 2003).

Destrinchando seu argumento, Lederach parte do pressuposto de que o conflito em si possui causas e efeitos que devem ser considerados para que a violência direta seja extinguida. Entretanto, diante da insuficiência dos mecanismos tradicionais de manutenção e construção da paz em identificar tais causas e efeitos e, consequentemente, de contê-los e minimizá-los, o autor traz novas propostas destinadas diretamente a equipes e programas de peacebuilding. Em Building Peace: Sustainable Reconciliation in Divided Societies, lançado em 1997 em um contex to no qual conflitos civis atingiam seu ápice em termos de quantidade e complexidade, o autor define-se enquanto um acadêmico "prático", o que implica que sua abordagem não se volta à mera sugestão de hipóteses, e parte do método indutivo como forma de apreender o conhecimento através da prática.

Voltando ao contexto histórico que permeia as principais reflexões do autor, tem-se que os conflitos contemporâneos possuem uma natureza empírica distinta daqueles ocorridos no pré-Guerra Fria. Os conflitos da segunda metade do século XX foram altamente influenciados pela bipolaridade: ainda que as duas superpotências não se enfrentaram em combates diretos, seus interesses refletiram-se em conflitos majoritariamente localizados no Sul. Com o fim da Guerra Fria, os conflitos civis, a despeito da contínua influência internacional, caracterizaram-se por serem enfrentamentos ocorridos majoritariamente em ambientes urbanos, em que gru- 
pos distintos entre si, por vezes com bases étnicas e religiosas, disputam a tomada dos governos de seus respectivos países.

A década de 1990, na qual o autor desenvolve seus estudos, é caracterizada pela expansão considerável de operações de peacekeeping empreendidas pelas Nações Unidas. Entre 1991 e 1999, 35 operações de paz tiveram início em inúmeras regiões que passavam por conflitos civis, enquanto esse número cai para 18 quando considera-se o período entre 1948 e 1990 (UN 2014). Levando em consideração o modelo seguido pelas Nações Unidas na execução dessas operações e as peculiaridades desses conflitos que emergem na nova ordem, Lederach engaja-se em propor alternativas que insiram as reivindicações locais na construção da paz. Então, busca-se discutir quais as características comuns às sociedades contemporâneas permeadas por conflitos, quais são as perspectivas para a construção da paz nestas e quais práticas e atividades são capazes de sustentar a transformação pacífica (Lederach 1997).

Ao propor a categorização de espaços transpostos por conflitos, o autor utiliza a denominação "sociedades profundamente divididas" para aquelas que passaram ou passam por alguma espécie de conflito armado. Nessas sociedades, na maioria das vezes pertencentes ao Terceiro Mundo, tem-se que os conflitos são pontuados por seu caráter intraestatal, porém com efeitos que transcendem os limites do Estado, atingindo especialmente os países vizinhos mediante fluxos de armamentos, recursos e migrantes e a criação de movimentos externos de oposição. Assim, os conflitos estimulam e agravam a instabilidade regional, e não apenas nacional.

A partir da interpretação desses fatos, Lederach (1997) define que os conflitos contemporâneos nas sociedades profundamente divididas são caracterizados pela multiplicidade de grupos em conflito. A difusão do poder nessas sociedades se dá em muitos aspectos, incluindo hierarquias, alianças e subgrupos dentro de grupos étnicos ou clãs. Outra característica de extrema importância é a existência de questões identitárias intrínsecas à sociedade, o que faz com que parte significativa da população se engaje no conflito por pertencer a determinada etnia, religião, clã ou região geográfica. Dessa forma, a extensão do conflito não se restringe às fronteiras estatais e seu prolongamento se deve, muito mais, à história comum compartilhada entre os grupos envolvidos e à grande carga de estereótipos que circundam as relações, com percepções e experiências subjetivas radicalmente diferentes entre si.

Lederach, após definir características comuns aos conflitos contemporâneos, parte para a definição de conceitos que sustentam as atividades propostas para essa nova forma de se construir a paz. Diante dos novos elementos que devem ser considerados, é nítido que as fórmulas-padrão 
de contenção do conflito, como a diplomacia tradicional estatal em sociedades profundamente divididas não agregam resultados satisfatórios. Assim, o ponto chave a ser trabalhado é a reconciliação, que consiste no restabelecimento de relacionamentos sustentáveis entre as partes. Isso se mostra necessário porque os grupos conflitantes estão intimamente ligados e terão que reconstruir a paz sob a mesma localidade geográfica e as mesmas instituições. Para que a reconciliação ocorra, cabe identificar as relações de interdependência entre essas partes e reconhecê-la como um espaço social no qual percepções e sentimentos possam ser compartilhados e transformados em relacionamentos futuros sustentáveis. Sem esse avanço inicial, torna-se inviável quaisquer tentativas de construção da paz diante da coexistência futura quase que essencial entre as partes (Lederach 1997).

Conforme o autor, peacebuilding consiste, portanto, em processos que comportam uma estrutura, e ambos - processos e estrutura - devem ser considerados para a compreensão do que se propõe enquanto solução. Quando se trata da estrutura, é importante assimilar os níveis de liderança presentes nas comunidades: o top-level, nível mais alto, é composto pelos líderes políticos e, por vezes, militares do conflito. São os maiores líderes representativos e são caracterizados por terem alta visibilidade, por expressarem o posicionamento oficial do grupo aos quais pertencem e por deterem poder e influência significantes, se não exclusivos. $\mathrm{O}$ middle-range, nível intermediário, agrega indivíduos que possuem certo papel de liderança, mas que não são atrelados ao governo ou a estruturas formais dos grupos. Esse papel de liderança não é baseado em poder político ou militar, mas no status e influência que exercem nos relacionamentos cotidianos: são indivíduos que ocupam posições importantes em setores específicos ou em redes primárias de grupos e instituições ou líderes que conseguem estabelecer diálogos entre comunidades ou regiões conflitantes. Por fim, o nível grassroots, que engloba os movimentos de base da sociedade, é composto pela parcela da população que está imersa no conflito e que empreende esforços constantes para sua própria sobrevivência. Geralmente, são líderes de comunidades locais, membros de ONGs ou líderes de grupos específicos, como grupos de refugiados (Lederach 1997).

De forma análoga e complementar aos níveis de liderança, estabelecem-se abordagens para o peacebuilding que podem ser centradas no estabelecimento de acordos formais entre as autoridades de cada grupo e as decisões são repassadas ao resto da população, em um movimento conhecido como top-down. Adicionalmente, podem ser também baseados na atuação de líderes da camada intermediária mediante desenvolvimen- 
to de redes e instituições em prol da conciliação, o que é chamado de middle-out. E, finalmente, tem-se a abordagem bottom-up, que consiste em discussões e estabelecimento de políticas comuns para que os líderes de base possam trabalhar no nível da comunidade em questões de paz e conflito.

Independentemente da abordagem a ser levada em conta, é importante que haja uma estrutura integrativa para que as necessidades da construção da paz sejam reconhecidas. Para o autor, o nível que tem maior potencial para estabelecer uma infraestrutura capaz de sustentar o processo de peacebuilding a longo prazo é o nível intermediário, visto que é capaz de captar a realidade enfrentada pela população, bem como ter acesso e voz frente às autoridades superiores. Essa conclusão do autor leva ao entendimento de que o local não deve ser romantizado e reduzido a práticas e tradições historicamente fundadas, visto que a dinâmica social envolve elementos muito mais atrelados à vivência comum e aos padrões de relacionamentos construídos em cada comunidade (Lederach 1997).

A partir da compreensão da estrutura, cabe compreender os elementos que definem o peacebuilding enquanto um processo. Primeiramente, é imprescindível que se tenha ciência de que o conflito nunca consiste em um fenômeno estático ou isolado, mas é um fenômeno dinâmico e dialético por natureza, baseado em relacionamentos fundados na percepção humana. Consequentemente, altera e é alterado pela interação humana. Dessa forma, o peacebuilding apresenta-se como um processo composto por uma multiplicidade de papeis, funções e atividades interdependentes, que tem como função principal criar e sustentar transformações e movimentos para a reestruturação de relacionamentos, envolvendo atividades que vão além de eventuais negociações específicas e que buscam ter relação direta com os objetivos de longo prazo de paz sustentável guiados pela geração de processos contínuos, dinâmicos e autorregenerativos (Lederach 1997).

Por fim, agregando todos os elementos dispostos acerca da estrutura e do processo, tem-se o que o autor chama de uma estrutura integrada que visa associar os componentes do peacebuilding de forma a responder às demandas dos conflitos contemporâneos, levando em conta as características gerais já expostas nesse artigo e as particularidades de cada estrutura social. A Figura 1 apresenta uma tentativa gráfica do autor de sintetizar suas ideias. 


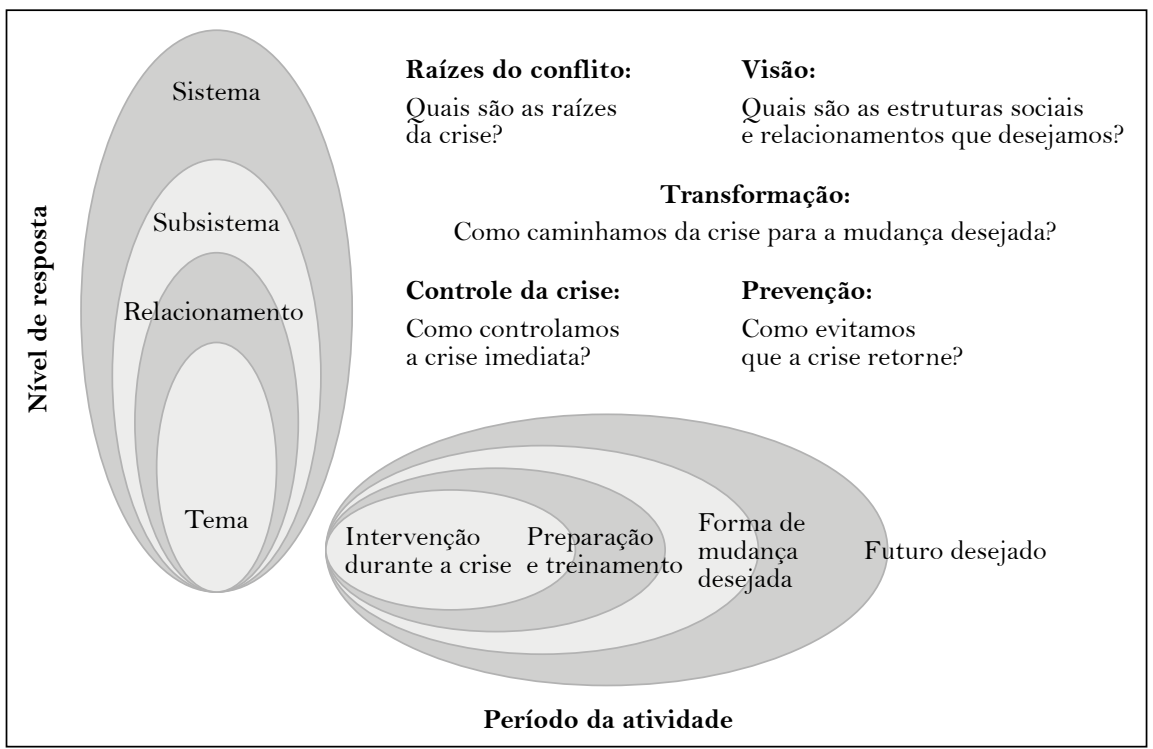

Figura 1 - Estrutura integrada do peacebuilding.

Fonte: Elaborado pelos autores a partir de Lederach (1997).

Assim, a relação processo-estrutura leva ao estabelecimento da infraestrutura para o peacebuilding, caracterizada por relações orientadas para a mudança social que busca transformar ciclos de violência em visões de interdependência. $\mathrm{O}$ cenário que se tem atualmente em termos de resolução de conflitos mostra que grande parte destes estão em um estágio intermediário entre a confrontação direta entre grupos e a negociação. Esse estágio não é positivo porque demonstra que as negociações não estão sendo, de fato, efetivas para que a etapa de confrontação direta seja superada. Os efeitos dessa estagnação são a perda da visão a longo prazo, o desvio do foco nas negociações e o fracasso em apreciar a multiplicidade e interdependência das atividades e funções do peacebuilding, que refletem a ineficiência dos programas imediatistas e centralizados de construção da paz implementado nos dias atuais (Lederach 1997).

Um dos questionamentos apontados pelos críticos à abordagem de Lederach volta-se à falta de componentes concretos que possam ser passíveis de mensuração ou avaliação. O próprio autor reconhece que o estabelecimento de padrões únicos nesse sentido se torna um desafio diante de fatores como a falta de linearidade quando se trata de construção de relacionamentos, visto que, em muitos casos, seguir um projeto à risca pode limitar os esforços de construção da paz a depender de como a comunidade 
responde aos esforços iniciais. Outro dilema enfrentado é relacionado ao tempo e à necessidade do peacebuilding em conectar as atividades atuais aos objetivos de longo prazo. Nesse sentido, é preferível tratar das evoluções da situação de conflito do que dos seus resultados estatísticos.

O terceiro desafio citado pelo autor consiste no repasse de eventuais informações coletadas que podem ser consideradas delicadas e íntimas para serem reportadas, em contraposição com a necessidade de transparência e prestação de contas ao programa. O último dilema apontado refere-se aos impasses institucionais, visto que as instituições levam em consideração os resultados ao invés da evolução e os projetos estruturados ao invés da infraestrutura. A partir disso, tem-se que os próprios métodos e padrões de mensuração devem ser contextualizados e adequados de acordo com as mudanças e os feedbacks por parte dos envolvidos (Lederach 1997).

Diante da sistematização trazida com os principais pontos tocados pelo autor, pode-se concluir que a população local e sua cultura são recursos indispensáveis para a construção da paz sustentável a longo prazo. Conforme Leonardsson e Rudd (2015, 826, tradução nossa) pontuam:

Ao adotar uma abordagem holística para a construção da paz, em que os atores domésticos em diferentes níveis sociais e atores internacionais são considerados importantes, Lederach enfatizou as visões para a paz inerentes entre as pessoas locais e a necessidade de a comunidade internacional reconhecer essas pessoas como recursos e não destinatários da construção da paz.

Destarte, o local pode ser compreendido como um espaço social no qual a reconciliação deve se projetar para que as partes em conflito possam estabelecer pontos de contato proativos e compartilhar suas experiências e percepções. A partir disso, a construção da paz se torna factível e com perspectivas de se perpetuar. Quando se trata da população local, esta deve ser considerada como o principal agente de peacebuilding. $\mathrm{O}$ reconhecimento internacional é importante para que suas ações sejam fomentadas sobretudo em termos de recursos. Todavia, impor modelos preestabelecidos aos processos locais de reconstrução social interfere negativamente na consolidação da paz.

\section{ROGER MAC GINTY E A PAZ HÍBRIDA}

Roger Mac Ginty, pesquisador associado à segunda virada local, atua em pesquisas relacionadas a processos de paz, violência política e respostas locais a intervenções internacionais de suporte à paz. Conduziu pesquisas de campo em nações que passaram por conflitos civis, incluindo alguns 
deles que já receberam intervenções por parte das Nações Unidas, como Bósnia-Herzegovina, Uganda e Líbano. Por pertencer ao segundo movimento de estudos que consideram o local na construção da paz, as influências que conduzem as reflexões do autor são relacionadas ao debate acerca da emancipação e da autonomia das regiões em conflito, propondo uma crítica às formas dominantes de manutenção e construção da paz.

$\mathrm{O}$ autor tece suas considerações à luz do contexto da década de 2000 , no qual as operações de paz iniciadas na década de 1990 não conseguiam alcançar a paz. Ainda que algumas missões tenham sido inicialmente desenhadas a partir de demandas locais, como a do Haiti (1990-1997) e a da Somália (1992-1995), estas acabaram por impor forças coercitivas diante dos resultados negativos, especialmente pela oposição de grupos locais a ações não adaptadas à sociedade na qual viviam. Dessa forma, Mac Ginty parte do reconhecimento das limitações do modelo vigente baseado na paz liberal a partir do entendimento de que este é idealizado por homens ocidentais pertencentes a Estados do Norte e que, por razões inerentes ao ambiente no qual é concebido, relega fenômenos sociais, políticos, culturais e econômicos locais (Bigatão 2015).

Apesar de ser largamente tomada como referencial na elaboração e execução de programas de peacemaking e peacebuilding, a proposta da paz liberal tem sido cada vez mais questionada. Seu fracasso pode ser atribuído aos mais diversos fatores, que vão desde a implementação de valores ocidentais e neoliberais que refletem os interesses dos Estados do Norte Global, até o caráter imediatista das intervenções, que faz com que as causas estruturais do conflito sejam ignoradas. Além disso, pode-se constatar que o modelo promove diferenciações entre as operações em diferentes sociedades baseadas em estereótipos e preconcepções equivocadas, como a intensificação do uso da força e coerção em comunidades não ocidentais - rotuladas como “ameaças" ao ocidente - e a persuasão enquanto principal estratégia em comunidades ocidentais. Uma das principais críticas, na qual o presente artigo se atém, consiste na falta de articulação das atividades às diferentes realidades encontradas nas sociedades pós-conflito, desconsiderando as especificidades e a capacidade de agência da população local. Para Mac Ginty (2011), os fenômenos que ameaçam a supremacia da paz liberal são as deficiências práticas dos programas intervencionistas e a consequente produção de resultados indesejados, a falta de confiabilidade no projeto por parte dos próprios agentes, as reações locais de resistência e as novas formas não liberais de intervenção lideradas por atores relevantes do sistema internacional.

O conceito de hibridismo adotado por Mac Ginty é proveniente de campos de estudo inicialmente distantes dos estudos para a paz. Surgido nas 
ciências biológicas, foi importado por abordagens sociais em estudos que buscavam compreender aspectos da colonização. Grosso modo, o hibridismo pode ser compreendido como a criação de formas culturalmente híbridas mediante o contato produzido pela colonização, ocorrendo mediante processos linguísticos, raciais, culturais, políticos, entre outros. Homi Bhabha, ao analisar a composição da sociedade indiana a qual pertencia, constatou que o contex to local era permeado por dois conjuntos de valores distintos entre si, mas que coexistiam: o dos colonizadores e o dos colonizados. Esses conjuntos eram desiguais, com convicções contraditórias entre si que questionavam e relativizavam uma a outra em todas as relações sociais, mas que neles emergia a identidade cultural através da criação de um chamado "terceiro espaço" (Bhabha 1994; Souza 2004).

Por essa via, a grande inovação de Mac Ginty (2011) é adotar o hibridismo como lente analítica para a investigação de processos de construção da paz. A partir do hibridismo, é possível desenvolver uma crítica mais aprofundada da paz liberal, promover releituras sobre a agência local de modo a afastar a romantização atribuída a esses sujeitos e, por fim, interrogar a natureza da paz contemporânea e as normas políticas, econômicas, sociais e culturais modeladas por esta. Para compreender o hibridismo, é importante ter ciência que esse processo não consiste em uma mera junção de duas entidades que compõem uma terceira, visto que uma interpretação nesse sentido desprezaria a complexidade do processo, que é composto por múltiplas partes que coexistem em um cenário dinâmico. Isso implica que o processo de hibridização central, surgido com a inserção de missões liberais de peacebuilding, deve ser entendido levando em conta que as partes também são frutos de processos prévios. Além disso, é importante que a hibridização seja vista como um processo que não ocorre de forma súbita e que não impõe a coexistência aos sujeitos. Via de regra, consiste em um processo gradual e cotidiano de negociação e entendimento mútuo. Finalmente, cabe destacar que existem diversos graus de hibridismo e hibridização: todas as partes são fruto de construções sociais híbridas, entretanto, deve-se reconhecer que existem sujeitos mais hibridizados que outros, assim como existem aqueles que resistem mais ao processo.

O hibridismo se mostra como uma crítica ao liberalismo nas intervenções de paz porque se contrapõe ao pressuposto de que a emancipação envolveria a abertura de mercados, democratização política e receptividade em relação às políticas determinadas por instituições e organizações internacionais. Em suma, o projeto liberal busca conter reivindicações de identidade porque acredita que estas consistem na causa do conflito e devem ser suprimidas, e esse posicionamento pode ser justificado pois se trataria de grupos permeados por violência e a opressão. Trazer o hibridismo como 
instrumento de análise instiga investigações aprofundadas sobre as origens e as aspirações de cada grupo levando em conta fatores culturais e identitários, e evitando suprimir grupos minoritários que seriam passíveis de exclusão em projetos liberais (Mac Ginty 2011).

Os processos híbridos de construção da paz podem ser financiados, fisicamente protegidos e até coordenados por atores externos; por vezes, podem até fazer com que a organização estatal e suas instituições reproduzam modelos liberais. Entretanto, essas estruturas de governança jamais serão duplicadas rigorosamente diante da inserção de elementos locais tradicionais. Conforme afirma Mac Ginty (2011, 75, tradução nossa): “Assim, a paz liberal se torna híbrida, projetando o internacional, mas também tendo que assumir alguns valores e costumes locais. Este é um processo de dois sentidos que tem impacto em todos os atores envolvidos”.

Para o hibridismo ser entendido enquanto um processo, é necessário compreender que este é uma variável em constante mudança que funciona em níveis distintos, por múltiplos meios e afeta aspectos significativos da vida cotidiana e, portanto, caracteriza-se por ser um processo de grande complexidade e longevidade. Com o objetivo de facilitar tal entendimento, Mac Ginty propõe um modelo de quatro partes que permite visualizar os eixos principais por meio dos quais a hibridização se concretizaria. Todavia, como todos os modelos, é uma abstração que não consegue captar toda a extensão e o dinamismo desse processo social tão complexo. O modelo sustenta que a hibridização é o produto da interação entre o poder de convencimento dos agentes da paz liberal para constranger outros atores em prol dos seus interesses, os incentivos promovidos por agentes da paz liberal para que os outros atores sigam seus interesses, a resistência dos agentes locais e sua capacidade de resistir, ignorar ou subverter as intervenções liberais e, por fim, as alternativas apresentadas pelos agentes locais para propor modificações e contrapropostas à paz liberal. A Figura 2 traz uma representação esquemática desse modelo. 


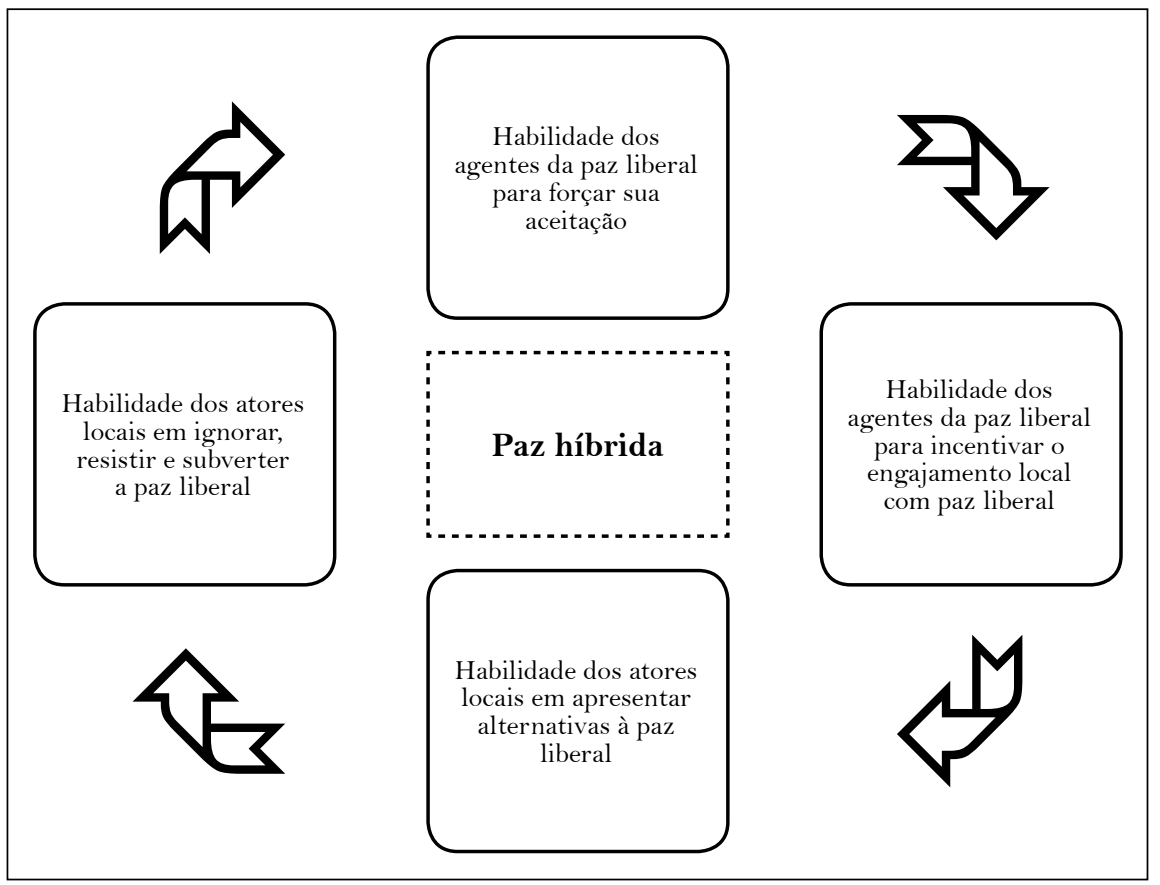

Figura 2-Paz Híbrida.

Fonte: Elaborado pelos autores com base em Mac Ginty (2011).

Cabe desenvolver maiores considerações sobre cada um dos componentes mencionados. Primeiramente, o poder de convencimento e conformidade por parte dos agentes liberais, é facilmente explicitado pelo uso da força e da violência direta por parte desses interventores, ainda que essa não seja a única técnica para se estabelecer a conformidade, que também pode ocorrer através de sanções, ameaças e imposições de ordem econômica (Mac Ginty 2011). Contudo, o instrumento de conformidade mais eficaz é a noção construída de que a paz liberal é a única opção possível, o que faz com que as escolhas dos agentes locais sejam limitadas. É importante reiterar que as intervenções liberais não são aplicadas com a mesma intensidade em todas as regiões, o que proporciona diferentes graus de hibridismo e diferentes graus de abertura para a inserção de outros atores nesse processo (Mac Ginty 2011).

O segundo componente da paz híbrida, que trata dos incentivos promovidos pelos atores liberais aos agentes locais, refere-se a supostos projetos e atividades destinados à emancipação da população, à cooperação e ao progresso social, mas que estão embutidos de interesses particulares e meca- 
nismos coercitivos. Dentre esses incentivos, o mais relevante é a própria garantia da paz, que é fortemente estimada em cenários conflituosos diante da pressão para que haja uma conciliação com os menores custos possíveis. Outros mecanismos que não devem ser desconsiderados são aqueles de natureza econômica e financeira, materializados através da abertura de mercados, de subsídios de reconstrução e de fornecimento de microcrédito, por exemplo. Esses incentivos servem bem aos objetivos liberais porque as sociedades emergentes de conflitos, geralmente, não têm muitas opções de acesso a recursos, o que leva à aceitação desse tipo de interferência. Assim, pode-se concluir que os incentivos e investimentos promovidos por agentes da paz liberal são, antes de mais nada, instrumentos que servem a interesses políticos (Mac Ginty 2011).

O terceiro componente consiste na capacidade dos atores locais de resistirem, ignorarem ou adaptarem-se às intervenções liberais. Ainda que a capacidade de mobilização de forças por parte dos agentes liberais possa ser questionável, é importante que a agência local não seja subestimada. Os atores locais, ou seja, todos os níveis dentro do Estado sujeitos à intervenção direta - governos, municípios, partidos políticos, sociedade civil, empresas e indivíduos - são capazes de imprimir mudanças sobre a paz liberal, transformando-a em uma paz híbrida. Enquanto alguns grupos optam por cooperar voluntariamente com o projeto liberal, outros grupos buscam questioná-lo em partes ou resistir completamente (Mac Ginty 2011).

Por fim, o quarto e último elemento sintetiza a habilidade dos atores locais em apresentar e manter formas alternativas de paz. Podem ser associados à ação cotidiana da população, que buscam prosseguir com suas realidades em um cenário pós-conflito. Todavia, convém ter em mente que os modelos que partem da agência local não necessariamente portam-se como dissidentes da ortodoxia liberal. Mac Ginty considera que é possível que modelos locais possam inclusive potencializar situações de violência estrutural consolidadas na sociedade (Mac Ginty 2011).

A partir dessa definição e categorização apresentada por Mac Ginty, é importante ressaltar que definir o que consiste o local e o que consiste o internacional resulta em uma simplificação analítica. Essas categorias não são estáticas e estão imbuídas de grande complexidade e sobreposição de fatores a serem considerados. Cabe concluir que o autor compartilha do entendimento do local enquanto o espaço no qual agências estão presentes em um conflito ou no ambiente pós-conflito, algumas das quais buscam identificar e desenvolver os processos necessários para a paz, com ou sem a ajuda internacional, de forma que a legitimidade em termos locais e internacionais seja concretizada. A paz estabelecida, então, por ser cotidiana, tem potencial para ser emancipatória (Mac Ginty; Richmond 2013). 
Ainda que a paz híbrida possa ser apontada como uma crítica relevante ao projeto da paz liberal, é possível questioná-la em alguns aspectos. Como devidamente pontua Nikolas Kompridis (2005), os conceitos de hibridismo e hibridização podem ser usados pelas autoridades de grupos de forma contraproducente a partir do momento que essa narrativa é utilizada para englobar toda a população em um único grupo "hibridizado", imprimindo certa normalização e neutralização às particularidades de cada grupo. Assim, o hibridismo acaba se convertendo em um conceito que predica a eliminação da diferença e nega a alteridade.

\section{CONSIDERAÇÕES FINAIS}

Cabe, nesta conclusão, salientarmos os pontos que consideramos mais relevantes das ideias de cada autor em um quadro comparativo, disposto a seguir:

\section{QUADRO 1}

Comparação entre as principais ideias de John Paul Lederach e Roger Mac Ginty

\begin{tabular}{|c|c|c|}
\hline & John Paul Lederach & Roger Mac Ginty \\
\hline $\begin{array}{l}\text { Contexto de produção } \\
\text { acadêmica }\end{array}$ & $\begin{array}{l}\text { Década de } 1990 \text {, compondo a primei- } \\
\text { ra virada local. Aumento expressivo } \\
\text { na quantidade de operações de paz } \\
\text { autorizadas pelas Nações Unidas. }\end{array}$ & $\begin{array}{l}\text { Década de } 2000 \text {, compondo a segun- } \\
\text { da virada local. Efeitos das operações } \\
\text { da década anterior passam a ser ana- } \\
\text { lisados e criticados. }\end{array}$ \\
\hline Referencial teórico & $\begin{array}{l}\text { Teorias de negociação internacional } \\
\text { voltadas à paz. }\end{array}$ & $\begin{array}{l}\text { Abordagens pós-estruturalistas e } \\
\text { pós-coloniais informando a análise } \\
\text { de peacebuilding. }\end{array}$ \\
\hline Problema de pesquisa & $\begin{array}{l}\text { Aperfeiçoamento das técnicas de re- } \\
\text { solução de conflitos para processos } \\
\text { de consolidação da paz sustentáveis. }\end{array}$ & $\begin{array}{l}\text { Proposição de novas abordagens que } \\
\text { superem a paz liberal. }\end{array}$ \\
\hline $\begin{array}{l}\text { Proposta alternativa } \\
\text { à ortodoxia }\end{array}$ & Transformação do conflito & Paz híbrida \\
\hline \begin{tabular}{|l|} 
Inspirações para a \\
compreensão do local
\end{tabular} & $\begin{array}{l}\text { Experiências pessoais como } \\
\text { mediador }\end{array}$ & Estudos de casos \\
\hline $\begin{array}{l}\text { Percepções acerca } \\
\text { do local }\end{array}$ & $\begin{array}{l}\text { O local é o espaço social no qual os } \\
\text { relacionamentos são reconstruídos e, } \\
\text { a partir disso, o locus no qual os ins- } \\
\text { trumentos para a construção da paz a } \\
\text { longo prazo são implementados. }\end{array}$ & $\begin{array}{l}\text { O local é um componente que com- } \\
\text { põe e empreende atividades em pro- } \\
\text { cessos de paz a partir da convergên- } \\
\text { cia, da submissão ou da subversão a } \\
\text { agentes da paz liberal. }\end{array}$ \\
\hline $\mathrm{O}$ interventor & $\begin{array}{l}\text { Consiste em um agente local devida- } \\
\text { mente capacitado capaz de promover } \\
\text { um ambiente propício à negociação } \\
\text { entre as partes e conciliar demandas } \\
\text { entre os diferentes níveis de liderança. }\end{array}$ & $\begin{array}{l}\text { Consiste em um agente com papel } \\
\text { ambíguo, dado que a depender da in- } \\
\text { teração, pode trazer efeitos benéficos } \\
\text { e ajudar a alterar situações de violên- } \\
\text { cia direta e estrutural, ou agravá-las. }\end{array}$ \\
\hline
\end{tabular}

Fonte: Elaborado pelos autores. 
À luz do Quadro 1 e das ideias previamente discutidas, podemos afirmar que, cronologicamente, o local era, primeiramente, considerado como aquilo que deveria ser padronizado, colonizado e civilizado, atribuindo uma versão romantizada ao espaço e à população ali residente. Muito disso se deve ao projeto empreendido pelas grandes potências europeias e pela consequente disparidade econômica e social entre os países pertencentes ao Norte Global e suas antigas colônias. O "redescobrimento" do local surge a partir das críticas aos programas ocidentais baseadas em seus efeitos perversos.

Ademais, para além de ser compreendido estritamente em termos geográficos, o local deve ser compreendido enquanto espaço desterritorializado, um locus constituído por redes, pessoas e atividades capazes de construir processos legítimos de estabelecimento de uma paz sustentável e duradoura. As colocações dos autores apresentados e da virada local podem ser questionadas, especialmente em termos materiais, visto que as iniciativas formais de paz demandam projetos e programas estruturados sob padrões comuns. Dessa forma, surgem críticas referentes a captação de recursos, ao estabelecimento de autoridades e à própria legitimidade dos processos locais de paz. Mac Ginty (2015) interpreta o local como um problema e uma solução. Utilizando-se de suas reflexões:

[O local $]$ foi considerado um problema por estar atrasado e disposto a abrigar identidades particularistas e exclusivas. É o espaço de conflito e subdesenvolvimento, e exige a consolidação da paz e a intervenção de desenvolvimento para ajudar a modernizá-lo, conectá-lo e pacificá-lo. Mas, ao mesmo tempo, o local também foi apresentado como uma solução. Ele foi lançado como um reservatório de sabedoria e engenhosidade. O idioma da resiliência foi implantado para reconstruir o local como capaz e até mesmo prudente [...]. O que essas duas visualizações do local mostram é que a categoria é maleável e capaz de ser feita e refeita (Mac Ginty 2015, 847, tradução nossa).

É importante que os estudos para a paz que consideram a agência local tenham em mente as particularidades e os aspectos pragmáticos envolvidos no estudo desse fenômeno, sem que se caia em equívocos recorrentes como a romantização do espaço e de seus indivíduos. O local pode constituir-se por tradições, indivíduos, relacionamentos, coletividades, redes e atividades as quais, conjuntamente, constituem um sistema de crenças e práticas adotadas por comunidades. No entanto, não há garantia de que, apenas por se levar em consideração a população local a paz necessariamente será sustentável. Ambos os autores argumentam a necessidade de esforços contínuos nessa empreitada. Apropriando-nos e modificando frase atribuída a John Philpot Curran, o preço da paz é a eterna vigilância. ${ }^{4}$ 


\section{REFERÊNCIAS}

Bigatão, Juliana de Paula. 2015. Do Fracasso à Reforma das Operações de Paz das Nações Unidas (2000-2010). Tese (Doutorado em Relações Internacionais), Programa de Pós-Graduação em Relações Internacionais, Universidade Estadual Paulista “Júlio de Mesquita Filho”, São Paulo.

Bhabha, Homi. 1994. The Location of Culture. Abingdon: Routledge.

DPKO. 2008. United Nations Peacekeeping Operations: Principles and Guidelines. New York: Department of Peacekeeping Operations.

Gomes, Aureo de Toledo. 2013. Da Paz Liberal à Virada Local: Avaliando a Literatura Crítica sobre Peacebuilding. Monções: Revista de Relações Internacionais da UFGD, Dourados, 2, 3, 46-76.

Kompridis, Nikolas. 2005. Normativizing Hybridity, Neutralizing Culture. Political Theory, 33, 3, 318-343.

Lederach, John Paul. 1997. Building Peace: Susteinable Reconciliation in Divided Societies. Washington: United States Institute of Peace Press.

Lederach, John Paul. 2003. Cultivating Peace: a Practitioner's View of Deadly Conflict and Negociation. In: Darby, John; Mac Ginty, Roger, Contemporary Peacemaking: Conflict, Violence and Peace Processes. Basingstoke: Palgrave Macmillan. 30-37.

Leonardsson, Hanna; Rudd, Gustav. 2015. The 'Local Turn' in Peacebuilding: a Literature Review of Effective and Emancipatory Local Peacebuilding. Third World Quarterly, 36, 5, 825-839.

Mac Ginty, Roger. 2011. International Peacebuilding and Local Resistance: Hybrid Forms of Peace. Basingstoke: Palgrave Macmillan.

Mac Ginty, Roger. 2015. Where is the local? Critical Localism and Peacebuilding. Third World Quarterly, 36, 5, 763-783.

Mac Ginty, Roger; Richmond, Oliver. 2013. The Local Turn in Peace Building: a Critical Agenda for Peace. Third World Quarterly, 34, 5, 763-783.

United Nations. 2014. List of Peacekeeping Operations 1948-2013. Disponível em: $<$ http://www. un. org/en/peacekeeping/documents/operationslist. pdf $>$. Acesso em: 27 dez. 2017. 
Öjendal, Joakim; OU, Sivhouch. 2015. The 'Local Turn' Saving Liberal Peacebuilding? Unpacking Virtual Peace in Cambodia. Third World Quarterly, 36, 5, 929-949.

Paffenholz, Thania. 2015. Unpacking the Local Turn in Peacebuilding: a Critical Assessment Towards an Agenda for Future Research. Third World Quarterly, 36, $5,857-874$.

Souza, Lynn Mario T. Menezes de. 2004. Hibridismo e tradução cultural em Bhabha. In Abdala Júnior, Benjamin (Org. ), Margens da Cultura: Mestiçagem, Hibridismo \& Outras Misturas. São Paulo: Boitempo Editorial. 113-133.

Richmond, Oliver. 2009. A Post-Liberal Peace: Eirenism and the Everyday. Review of International Studies, 35, 3, 557-580.

Silva, Francine Rossone. 2012. A Paz Liberal nas Operações de Peacebuilding: o "Local" e os Limites da Crítica. 2012. Dissertação de mestrado em Relações Internacionais, Instituto de Relações Internacionais, Pontifícia Universidade Católica do Rio de Janeiro, Rio de Janeiro.

Wright, Walter A. 2004. John Paul Lederach: A Peacebuilder Bibliography. Disponível em: <http://www. mediate. com/articles/wrightw2. cfm>. Acesso em: 28 out. 2017.

Zartman, I. Willian. 2003. The Timing of Peace Initiatives: Hurting Stalemates and Ripe Moments. In: Darby, John; Mac Ginty, Roger, Contemporary Peacemaking: Conflict, Violence and Peace Processes. Basingstoke: Palgrave Macmillan. 19-29.

Schierenbeck, Isabell. 2015. Beyond the Local Turn Divide: Lessons Learnt, Relearnt and Unlearnt. Third World Quarterly, 36, 5, 1023-1032. 


\section{NOTAS}

1. Os autores agradecem a Fundação de Amparo à Pesquisa do Estado de Minas Gerais (FAPEMIG) pelo apoio mediante projeto de pesquisa código APQ-00605-17.

2. Tomando como referência a publicação conhecida como Doutrina Capstone (DPKO 2008), podemos dividir as atividades da Organização das Nações Unidas com vistas à resolução de conflitos em 5 tipos: conflict prevention, o uso de medidas diplomáticas para se evitar que tensões inter e/ou intraestatais culminem em violência aberta; peacemaking, ou o uso de medidas para se findar com conflitos em andamento; peacekeeping, ou uso das técnicas necessárias para se preservar a paz após um cessar-fogo entre as partes; peace-enforcement, que se refere ao uso de meios coercitivos, inclusive militares, com autorização prévia do Conselho de Segurança, para se findar com o conflito; e as atividades de peacebuilding, foco deste trabalho.

3. I. William Zartman é, talvez, um dos mais conhecidos negociadores internacionais, cuja contribuição é reconhecida por ser voltada à resolução de conflitos. As obras do autor, concentradas na década de 1970, propõem técnicas que buscam aprimorar os processos de mediação e arbitragem para a resolução de litígios.

4. A frase original de John Philpot Curran é "O preço da liberdade é a eterna vigilância”. O autor irlandês foi conhecido nos séculos XVI e XVII por ser um notável orador e jurista e profundo conhecedor da sociedade do seu tempo. 
DA TRANSFORMAÇÃO DE CONFLITOS À PAZ HÍBRIDA:

UMA ANÁLISE DAS IDEIAS DE JOHN PAUL LEDERACH E ROGER MAC GINTY

\section{RESUMO}

O artigo compara as percepções do "local" para John Paul Lederach e Roger Mac Ginty a fim de estabelecer as semelhanças e diferenças entre suas contribuições. Apesar de serem incluídos na mesma abordagem de estudos para a paz, os autores apresentam divergências substanciais. Enquanto John Paul Lederach propõe a Transformação de Conflitos como forma de se alcançar a paz sustentável a partir da agência local, Roger Mac Ginty retoma o conceito de hibridismo para analisar a relação dos agentes locais e internacionais nesse processo.

Palavras-chave: Virada Local; Peacebuilding; Transformação de Conflitos; Paz Híbrida.

\section{ABSTRACT}

The article compares the perceptions of the "local" in the work of John Paul Lederach and Roger Mac Ginty. Although they are usually included in the same category, the authors present significant divergences. While John Paul Lederach proposes Conflict Transformation as a way to achieve sustainable peace, Roger Mac Ginty proposes the concept of hybridity to approach the interconnections of local and international actors in this process.

Keywords: Local Turn; Peacebuilding; Conflict Transformation; Hybrid Peace. 